\title{
Reseña de la Investigación \\ “El Maestro Rural” de Díeter Pass
}

Dieter Pass

“El Maestro Rural”, Editora Guadalupe. Bogotá, 1979.

Este trabajo está realizado dentro del marco de los estudios rurales, preocupación prioritaria de la última década y busca establecer la posible incidencia del maestro rural en el desarrollo de la comunidad, como promotor de cambio y líder de la población rural.

La primera parte de la investigación ofrece un diagnóstico del aparato escolar colombiano, mostrando las diferencias entre área rural y urbana y sector oficial y privado. Presenta algunos indicadores de la eficiencia interna del aparato escolar, así como un panorama de la estructura administrativa del sector educativo a nivel nacional y regional. Tiene sólo la intención de ubicar al lector desorientado en esta problemática y es irrelevante dentro del contexto general de la investigación.

El valor de este estudio radica en hacer un análisis de tipo cualitativo entre educación y desarrollo rural a través del agente estatal en el campo (el maestro) y la comunidad rural. La metodología utilizada fue primordialmente la entrevista estructurada complementada con evaluación de literatura secundaria e informes de investigación, así como charlas con especialistas en el tema. La entrevista estructurada aplicada a una pequeña muestra de maestros rurales, tiene gran importancia en lo que se refiere a entrevistas demoscópicas, consultas orales, tipificadas, de personas escogidas de acuerdo con una muestra que permite al investigador social la recolección de un material primario de estudio.

Las áreas de acción del maestro rural encontradas por Pass van desde las propias al ámbito endógeno del aparato escolar hasta las extra-profesionales (dotación de mobiliario escolar, freno a la deserción mediante una labor de convencimiento a los padres, hasta enseñanza de técnicas agropecuarias y de salud e higiene a los miembros de la comunidad).

Encontramos un testimonio valioso a través de la trascripción de cintas sobre las diversas modalidades asumidas por la acción del maestro, las cuales pueden estar influenciadas por las expectativas de las autoridades educativas -que desempeñe funciones promotoras - o bien por el simple hecho de constatar la difícil situación social en la cual se desenvuelve ejecutando entonces acciones de tipo paternalista; Pass muestra entonces como el agente educativo debe responder a perfiles y niveles de exigencia bajo el carácter de voluntariado.

Pass explora las relaciones maestro-comunidad desde varios ángulos: obligatoriedad ante un patrón político, relaciones con líderes locales, intereses y expectativas manifiestas de la comunidad rural, conflictos de intereses y divergencias de opinión con los habitantes de las veredas.

El hecho de indagar sobre la posibilidad real de que el maestro rural se cambie a partir de su formación y experiencia docente en promotor de desarrollo social de la comunidad, se inscribe dentro del Programa de Capacitación para Promotores de Desarrollo Social 
Rural adelantado por la Escuela Superior de Administración Pública —ESAP_ y la Fundación Friedrich Naumann.

Es significativa la concepción de desarrollo social sobre la cual se desplaza el autor (mejoramiento de las condiciones de vida de los habitantes del campo a través de servicios auxiliares o acciones que buscan reeducar e informar a fin de modificar actitudes, hábitos y comportamientos considerados lesivos para el desarrollo en comunidades eminentemente marginales). Nos encontramos con el nuevo rol que deberán asumir los conocimientos como instrumentos o procesos técnicos que ayuden a los individuos, a la sumatoria de éstos —comunidades- en la búsqueda de soluciones a sus necesidades y problemas.

Una ratificación de esta concepción como política de las agencias internacionales para la década del 80, la encontramos en el marco expuesto por la UNESCO en la elaboración de programas que logren convertirse en "Alternativas para la Educación de los Grupos menos Favorecidos".

Este material de Dieter Pass servirá seguramente para posteriores estudios que requieran información primaria y como punto de partida de explicaciones sobre la conducta del maestro y sus relaciones con las comunidades marginadas.

Clara Eugenia Torres 